\title{
The origin, evolution and future of carbonate clumped isotope geochemistry \\ JOHN EILER
}

Caltech

Presenting Author: eiler@gps.caltech.edu

Carbonate clumped isotope thermometry was first suggested in 1947 but lay fallow because its technical hurdles seemed insurmountable. Here we consider what factors allowed it to grow from a beach head of capabilities and proof-of-concept applications into a broad discipline combining technology development, fundamental theory, experimentation, and diverse uses; we also ask how this field might evolving further in the future.

This subject has been dominated by technology, methods and standardization, as there can be no carbonate clumped isotope geochemistry without measurements of extreme isotope ratios $\left(\sim 10^{-5}\right)$ with extreme precision $\left(\sim 10^{-5}\right.$ to -6$)$. Key elements of our success include: the prior existence of well-engineered gas source IRMS's; work with manufacturers to identify, understand and fix technological issues; and collaborations to address confusing problems in interlaboratory standardization and thermometer calibration. Arguably, the field's greatest accomplishment has been quickly recognizing, addressing and retiring problems that could have undermined its impact for decades

The ubiquity of carbonates and importance of climate, the hydrosphere and biomineralization are what drive most applications of this field. A surprise has been the novel ways of studying histories of crustal rocks using the kinetics of clumped isotope re-ordering in solids. All these tools will be re-imagined, as ${ }^{13} \mathrm{C}-{ }^{18} \mathrm{O}$ clumping is complemented by ${ }^{18} \mathrm{O}-{ }^{18} \mathrm{O}$ clumping and subtle ${ }^{17} \mathrm{O}$ anomalies, letting us recognize and interpret nonequilibrium isotope effects. This will demand that we create laboratories able to perform all three of these measurements, well and quickly on a single sample. But the greatest unmet need may be for more fundamental theoretical and experimental study of the material- and process-specific isotope effects involving these complex observations.

Isotope ratio analysis by IR spectroscopy will work its way into our field, increasing access to analytical instruments and possibly yielding field instrumentation. There are many new clumped isotope technologies and applications that built on the carbonate field, such as high-resolution IRMS for alkanes, $\mathrm{N}_{2} \mathrm{O}$, $\mathrm{N}_{2}$ and $\mathrm{H}_{2}$, and Fourier-transform, particularly Orbitrap ${ }^{\mathrm{TM}}$, MS for practically anything else. These sub-disciplines have little interaction with the carbonate clumped isotope community, but we should expect to see cross-hybridization of technologies, methods, and theoretical insights and combined applications. 